\title{
The Study of Parameters and Reliability of Low-intensity Irrigation in the Conditions of Azerbaijan
}

\author{
RAS BH Aliyev ${ }^{1}$ and RAE ZH Aliyev ${ }^{2 *}$ \\ ${ }^{1}$ Erosion and irrigation Institute of NAS of Azerbaijan Republic, Azerbaijan \\ ${ }^{2}$ Institute of Soil Science and Agrochemistry of NAS of Azerbaijan, Azerbaijan
}

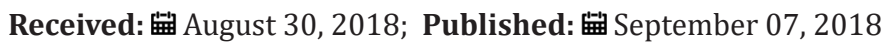

*Corresponding author: RAE ZH Aliyev, Institute of Soil Science and Agrochemistry of NAS of Azerbaijan, Azerbaijan

\section{Introduction}

In recent years, both in the Republic and in the CIS and far abroad are developing low-intensity stationary systems of irrigation, consisting of Micro Sprinklers, impulsive actions, aerosol auto oscillatory action sprinkling irrigation, auto oscillatory action auto oscillatory action combined, the drip, drip pulsing and a number of others. This is because low irrigation system has a number of significant advantages over other methods of irrigation. Especially promising the creation of automated sprinkling systems impulse machines, combined, auto oscillatory action stepper auto oscillatory action rocker type, pulse-airborne apparatus auto oscillatory action, etc. It should be noted that these systems allow to reduce the capital cost of their construction, also ensure the principle as "sprinkling" or "drip" in condition of daily water use plants. That is to create optimal conditions for the growth and development of plants during their growing season (Figure 1).

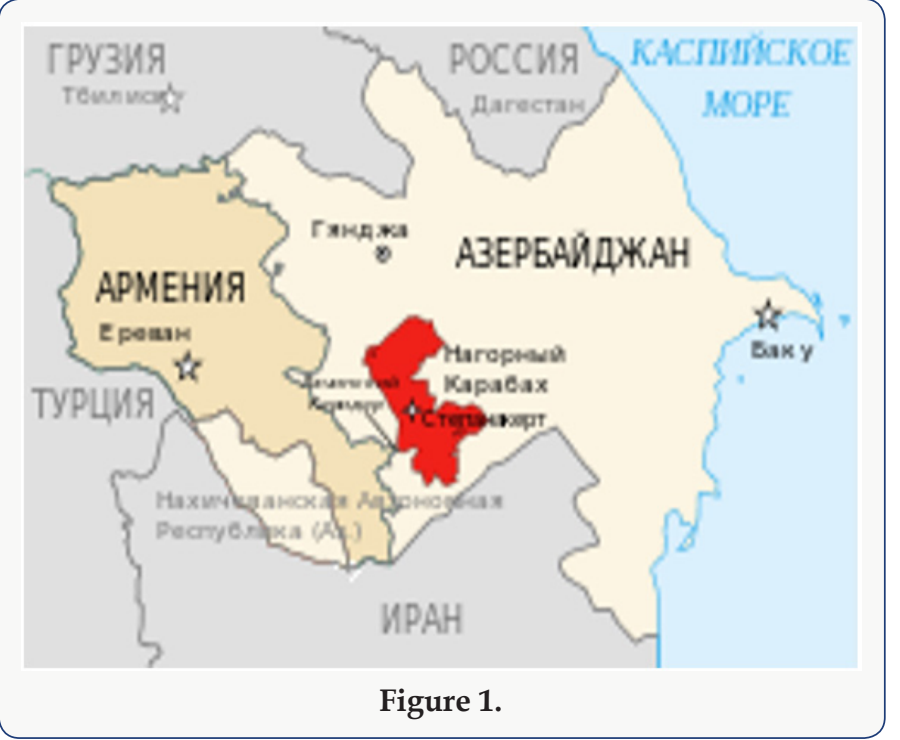

\section{Moves the study}

Automated watering crops the basis for high yields and productivity. Therefore, from the elements and devices used automatics require reliable and uninterrupted operation. Therefore, starting from the design stage through these devices and the production and operation, reliability issues, because the problem of reliability is not only technical, but also an important economic task. Reliability theory developed in recent decades, offers a great opportunity for a qualitative assessment of the reliability of existing irrigation technique, including micro irrigation systems. Reliabilitythis property of equipment or system to perform specified functions to maintain their performance within the required period or time required. From among the existing irrigation technique, stationary sprinkling system consisting of a large number of similar elements in a specific order on the field and required for the irrigation of crops. Determining the reliability of one of these elements will decide the reliability of systems. Reliability issues fixed irrigation systems in particular, equipped with sprinkling installations engaged in many of the scientists in the former Soviet Union and abroad. To examine the elements of the calculation on reliability of low-intensity sprinkling (for example pulse sprinkling auto oscillatory action) should consider the technological feasibility and sprinkler systems. Optimal low irrigation system parameters were determined by us by searching for the specific functions listed minimum cost with uD. Depending on the area of the system $S$; aspect ratio $\theta$; the cost of the system $(\mathrm{Q})$; Mr pressure corresponding to the pressure dictating point; conditional irrigation period $t_{\text {at }}$ equal $\frac{i}{q 3600}$ where, $\mathrm{m}$ irrigation norm, $\mathrm{m} ; \mathrm{q}$ /-maximum ordinate hydro-module $\mathrm{m} / \mathrm{s}$ ).

Number of distribution pipelines $(\mathrm{N})$; the distance between irrigation technique (sprinkle plants) $\mathrm{l}$; $\mathrm{x}$ factor, equal with the placement of devices on square 0.2 ; the length of the i-th pipeline 
system $l_{(\mathrm{i})}$ its diameter (D) $)_{(\mathrm{i})}$ and discharge $Q_{(\mathrm{i})}$, the coefficients $(\mathrm{k}),(\mathrm{m}), \beta$-dependent roughness of the internal the surface of the pipes; costs of irrigation Engineering (sprinkler devices, etc.). With $\mathrm{g}$ and the pressure Sn site; the cost of one $\mathrm{kW} / \mathrm{h}$ of electricity; $\psi$, coefficient $\eta$ pump unit equal to 0.7 coefficient of non-uniformity of flow

$$
\hat{E}_{i}=\frac{2 r l_{n} p}{p-1)(r+1}
$$

gde, $\mathrm{r}$ - ratio splash start $\mathrm{P}_{2}$ to pressure end splash $\mathrm{r}_{1 \text { ), }}$ equal to 1.02-1.25; factor $e_{0}=e_{1}+{ }_{2}\left(e_{1}, e_{2}\right.$-regulatory factors of efficiency of capital investments and annual deductions for depreciation and repairs); coefficients (b), (d) dependent on the material and the cost of pipe laying and operating costs of the attendants $e_{(n)}:[1,2]$

$$
\begin{gathered}
\mathbf{C}_{\text {UD }}^{\mathbf{n}}=\mathrm{S}^{1}-\left[\mathrm{E}_{0} \sum\left(\mathrm{a}+\mathrm{b}(\mathrm{D})_{(\mathrm{i})}^{(\mathrm{a})}\right) \mathbf{l}+\left(\mathrm{C}+\sum \mathrm{C}_{\mathrm{g}}\right)+\mathrm{BQ}\left(\mathrm{H}+\sum \mathrm{KQ}_{\mathrm{i}}^{\beta}\right.\right. \\
\left.\left.\mathrm{D}_{\mathrm{i}}^{-\mathrm{m}} \mathrm{l}_{\mathrm{i}}\right)+\mathrm{e}_{(\mathrm{n})}\right](2)
\end{gathered}
$$

Studies have shown that the most economical option is the simultaneous operation of all sprinkler devices system, i.e., when the system is produced by the limit dispersal of current irrigation [3] in this case has a minimum at points determined by the expressions:

$$
\begin{gathered}
N=\frac{n 2^{H n}}{1-n} \\
S=\frac{Q^{\frac{1+n}{2}} S^{\frac{1-n}{2}}}{l^{l-n}} \\
L=\left[\frac{\gamma \lambda(1-n)^{l+n}}{x B\left(n^{2 n}\right)^{n}}\left(q^{\prime}\right)^{n-1}\left(\frac{S}{\theta}\right) \frac{n^{2}}{2}\right]^{(n 2-2 n+2)^{-1}}
\end{gathered}
$$

Where is

$$
\begin{aligned}
& n=\frac{\alpha(\beta+1)}{\alpha+m} \quad \lambda=(m+\alpha)\left(\frac{B \kappa}{\alpha}\right)^{\frac{\alpha}{\alpha+m}}\left(\frac{E 。 b}{m}\right)^{\frac{m}{\alpha+m}} \\
& \gamma=1-\frac{n}{2}-\frac{n(1-n)}{6} \mid \quad B=\frac{1000}{102 \eta} \psi K H
\end{aligned}
$$

Substituting in the formula (3) and (4) coefficients corresponding to steel pipelines $(\mathrm{d}=1.4 ; \mathrm{m}=5.1 ; \beta=1.8 ; \mathrm{K}=$ 0.00107; $\mathrm{In}=50 ; \mathrm{E}_{0}=0.2 ; \mathrm{To}_{\mathrm{n}}=1.1$ ), obtain payment formula to determine and that for ease of use, represented by nomogram (Figure 2). Similar monograms built and for pipes made of plastics and other materials. Optimal pipeline diameters (D) ${ }_{\text {opt' I number }}$ of irrigation pipelines $\mathrm{x}$, suspended from the distribution pipeline, number of sprinkler devices on the polynom pipeline $\mathbf{y}$ define the following ratios:

$$
D o \pi \tau=\left(\frac{B K m}{E o \alpha b}\right)^{\frac{1}{\alpha+m}} Q^{\frac{\beta+1}{\alpha+m}} \quad \chi=\frac{1}{2 l} \sqrt{\frac{S}{\theta}} \quad y=\frac{2 \sqrt{S \theta}}{N}
$$

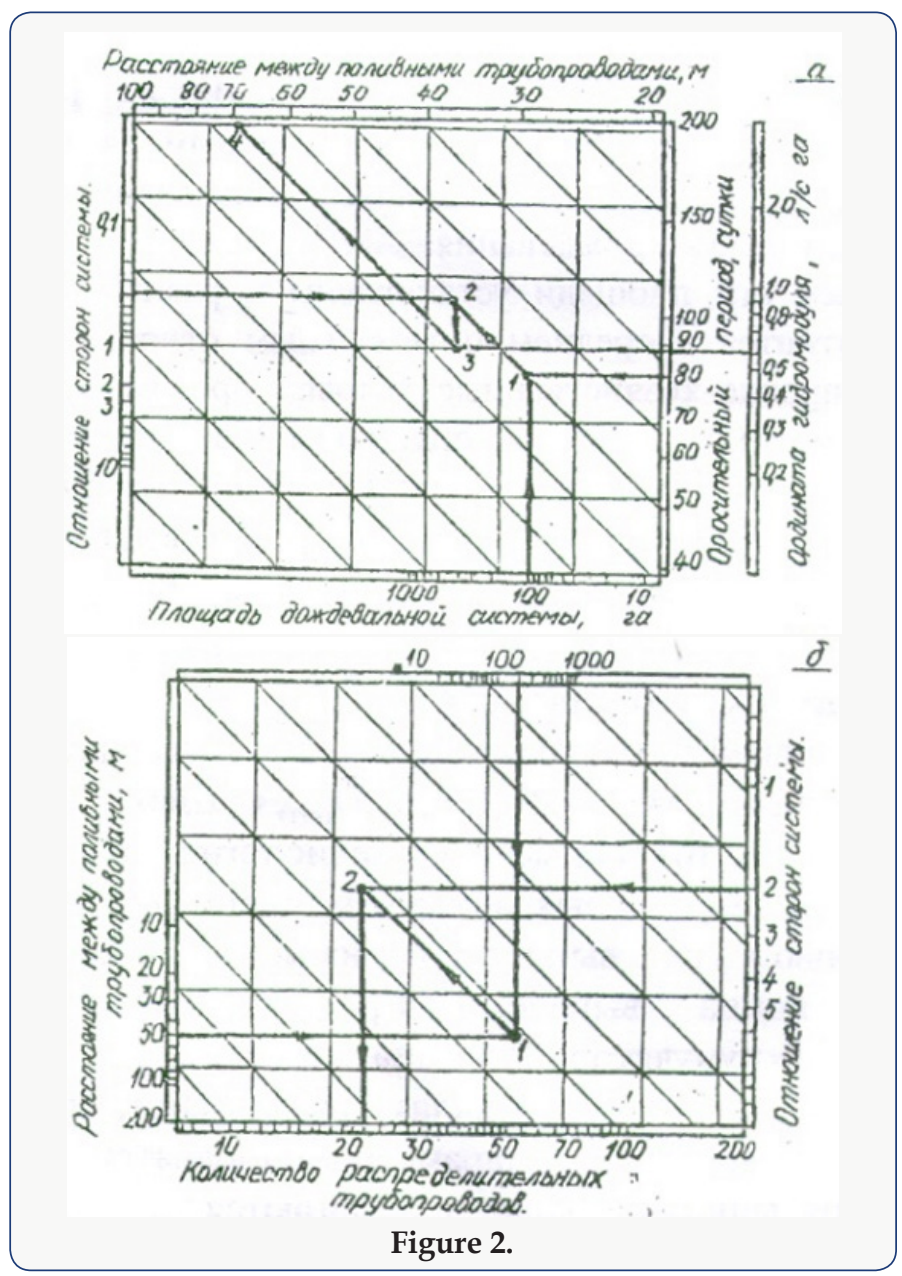

If you change the original parameters $\mathrm{S}, \mathrm{q} /, \theta, \mathrm{m}$ ) within: $<=30$ $\mathrm{S}<=300 \mathrm{ha}, 100.3^{-7}<=\mathrm{q}^{/}<=1.0 \times 10^{-7} \mathrm{~m} / \mathrm{s},<0.25=\theta<=4,0.3$ $<=\mathrm{M}<=1.0 \mathrm{~m}$

$1000 \mathrm{~m}^{3} / \mathrm{HA}$, the optimal system settings change within: $35<=$ $\mathrm{l}<=135 \mathrm{~m} ; 3<=\mathrm{N}<=65 ; 1=<\mathrm{x}<=50$; and $1<=\mathrm{y}<=33$. Being attached to squares, laid down specific natural-economic conditions define systems parameters of irrigation on low-intensity pulsed example sprinkling [4]. Consider these square set and equal to 150400 ha and have an average optimal relationship of the parties 1-3 and natural-economic conditions irrigation norm $0.35-0.75 \mathrm{~m}$ and a maximum ordinate $0.6 \times 10$ hydro-module ${ }^{-7}-1.0 \times 10^{-7} \mathrm{~m} / \mathrm{s}$.

Averaged source data $S=200 \mathrm{ha}, \theta=2 ; \mathrm{M}=0.55 \mathrm{~m}, \mathrm{q} /=0.8$ $\mathrm{x}^{-7} \mathrm{~m} / \mathrm{s}$, the following optimal system settings $\mathrm{l}=50 \mathrm{~m}, \mathrm{~N}=22, \mathrm{x}=$ $10, y=8$ obtained using the following programs and formulas (4.5). For other crops and natural-economic conditions these parameters are defined similarly. Obtained values of $\mathrm{N}, \mathrm{l}, \mathrm{x}, \mathrm{y}$, (D) ${ }_{\text {opt }}$ I -enable you to define the basic construction and technological parameters of irrigation equipment (impulse sprinklers apparatus self-oscillating action): as head $\mathrm{n}_{2}$, corresponding pressure start splash $\mathrm{RV}_{2}$, head $\mathrm{n}_{1}$, the pressure end splash $\mathrm{r}_{1}$; constructive volume pneumatic accumulator $\mathrm{W}_{0}$ and nozzle diameter (D) $[3,5]$. Based on the submissions of works of scientists of the world, and 
the results of Erosion and irrigation in the Institute research on some definition NANA parameters of irrigation technology in conventional machines, sprinkler machines pulse actions, etc., for which we offer the following characteristic control to determine the basic parameters of pulse devices depending on pressure. But corresponding to the initial pressure pneumatic accumulator $\mathrm{p}_{0}$ and the corresponding atmospheric pressure $\mathrm{p}$ and cross -sectional areas, bringing the pipeline $\omega_{2}$ inlet flow coefficients pneumatic accumulator $\mu_{1}$ and $\mu$ nozzles $_{2}$, resources pneumatic accumulator $t^{*}$, sprinkler apparatus $\mathrm{N}^{*}$, the coefficients that depend on the value of sprinkler apparatus $(d)_{1}$ and $(d)_{2},[1,2,3,7]$.

$$
\begin{aligned}
& \frac{H_{o} W_{o}\left(H_{2}-H_{1}\right)}{H_{1} H_{2}\left(T_{1}+T_{2}\right)}=k_{1} q^{\prime} l^{2} \\
& \mathrm{~W}_{0}=\mathrm{R}^{2}=\sqrt{\frac{a_{1} p M H_{1} H_{2} T^{*}}{H_{0}\left(H_{2}-H_{1}\right) a_{2} N^{*}}} \\
& \mathbf{D}=\left[\frac{H_{1}^{0.3}}{6.6} \cdot \frac{H_{2} / H_{1}-1}{\left(H_{2} / H_{1}\right)^{0.3}-1}\right]^{7.5} \cdot 0^{-2}
\end{aligned}
$$

It should be noted that equation (6) matches the water supply and water plants, and equation (7) and (8), respectively, the optimum size of sprinkler devices and agro technical requirements and quality of rain (the number of sprinklers drops with a diameter of more than 1.0-1.5 mm in overall flow rain Jet should be less than $10 \%$ ). Each group of $\mathrm{m}, \mathrm{q}, \mathrm{S}, \theta$ correspond definite values $\mathrm{x}, \mathrm{y}, \mathrm{N}, \mathrm{l}$ and system settings $h_{2} n_{1}, W_{0}$, D pulse settings of the apparatus. Bearing in mind that the real system $t_{1}=t>{ }_{2}$ and sum of hydraulic resistance to worst according to the terms of the pnevmogidroakkumljatora filling system $\sum \xi=>1$, equation (6) you can submit in the form: $[1,7]$

$$
\begin{gathered}
H I=\sqrt{\left(\frac{H_{2}^{2}+2 C^{2} H_{2}}{2 C^{2}}\right)^{2}+\frac{H_{2}^{3}-C^{2} H^{2}}{C^{2}}}-\frac{H_{2}^{2}+2 C^{2} H_{2}}{2 C^{2}} \\
C=\frac{k_{1} q}{\mu_{1}\left(\omega_{1} \sqrt{2 g}\right.} \quad \mu=\sqrt{\frac{\left(A q^{n_{1}}\right)^{1.3}}{\gamma a_{1} l F(x \cdot y \cdot N)}} \quad A=\left(\frac{B k m}{E_{0} \alpha b}\right)^{\frac{1}{\alpha+m}} \\
F(x \cdot y \cdot N)=y^{1-n_{2}}+x \frac{1-n_{2}}{1.3 n_{1}}+\frac{N^{1-n_{2}} y^{1-1.3 n}}{x^{1.3 n_{1}} 2^{1.3 n_{1}-n_{2}+1}} q=q^{1} l^{2} \\
\omega=0.785\left(A q^{n_{1}}\right)^{2} \quad n_{1}=\frac{\beta+1}{\alpha+m}=0.44 / n_{2} /=/ 2-5,3 n_{1} /=0,33
\end{gathered}
$$

$\mathrm{Q}_{\mathrm{i}}$-factor of 2.64 for steel pipes. $10^{-3}$ /Equation (7,8 and 9) together with the formula for Ap Ruseckogo represent a closed system of equations. The below Figure 2 provides a graphical solution of this system. Knowing the economic radius of action impulse apparatus and setting from system (=3-5), the search for a solution should lead to corresponding with curves in the following order and and $_{4}$, and and $_{10}$ for $\mathrm{s}=3$, by and and $_{5}$ and $_{8}$ and $_{11}$ when $\mathrm{c}=4$ and $_{3}$ and $_{6}$ and $_{9}$ and ${ }_{12 \text { when }} \mathrm{c}=5$. Parameters of sprinkler unit with intermediate values with determined by interpolation. Using the results obtained previously, define the structural and technological parameters of pulse apparatus for the same natural-economic conditions. With the placement of devices on the squares economy its radius $\mathrm{R}=21-35$, and $\mathrm{c}=3[1,3]$. Using monographs $\mathrm{s}$ and the input values to and (C) pulse parameters are as follows:

$$
(\mathrm{P})_{1}=450 \mathrm{kPa}, \mathrm{P}_{2}=700 \mathrm{kPa}, \mathrm{W}_{0}=0.19 \mathrm{~m}^{3}, \mathrm{D}=20 \mathrm{~mm} \text {. }
$$

To address the complex of actions on system reliability is reliability elements sprinkler systems. Research of reliability indicators of basic elements of fixed sprinkler system are the results of theoretical and experimental research, evaluated, tele control devices noise immunity parameters dispersion, irrigation norms precipitate individual sprinkling and installed types and parameters of distributions of operating time to failure of the main elements of the systems sprinkling [3,4]. In moments the adoption of tele control device command "select object" in the network of technological pipelines occur transients. Found that the pressure $\mathrm{p}$ can be set to lower static pressure reconfiguring tele control devices $\mathrm{r}_{0}{ }_{0}$ and duration of exposure of the false signal can reach $0.15-1.2 \mathrm{sec}$. Received the following experimentally confirmed the dependence between team processing time signal $t_{k}$, swing Rod $\mathrm{h}$ effective membrane area $(\mathrm{F})_{\mathrm{e}}$, a cross section of tube connecting the technological pipeline with working hydraulic factor $\omega$ dental rigidity to the recoil spring ${ }_{2}$, specific gravity $\gamma$ water ${ }_{\mathrm{b}}$ and the acceleration of gravity $(\mathrm{g})$ :

$$
t_{k}=\frac{F_{o}}{\mu \omega k_{2}} \sqrt{\frac{2 F_{0} \gamma b}{g}}\left[\sqrt{h K_{2}+F_{9}\left(P_{o}^{\prime}-P\right)} \sqrt{F_{9}\left(P_{o}^{\prime}-P\right)}\right]
$$

According to the formula (10) evaluated the time reconfiguring device automated tele control. At instant slide. pressure in the hydraulic drive to atmospheric pressure, $\mathrm{kPa}$, corresponding pressure 340 item Chooser requires 0.34 c 1.5 times greater than the duration of a false signal. (10) allows you to not only assess the time reconfiguring devices of automated process control systems tele control channel irrigation, but to appoint him constructive value parameters in accordance with the requirements of noise items tele control systems [3]

Start pressure dissipation of impulsive actions self-oscillatory apparatuses splash leads to dispersion of their volumes $\Delta$ splash W layer and therefore rain $\mathrm{m}$, so how are they related dependencies.

$$
\Delta W=\frac{P_{o} W_{o}\left(P_{2}-P_{1}\right)}{P_{1} P_{2}} \text { and } M=\Delta W \frac{N_{o}^{\#}}{S_{1}}\left(N_{o}^{\#} \cdot S_{1}\right)
$$

(the number of cycles of performance in a year and its service area). Testing of pulse (100 picks) and the subsequent processing of the received data found that distribution of $r_{2}$ and $r_{1}$, subject to the normal law with coefficients of variation of $v \mathrm{P}_{2}=0.04$ and $v \mathrm{P}_{1}=$ 0.093. Bearing in mind

A what

$$
\bar{M}=\frac{\Delta W N_{o}^{\#}}{S_{1}} \text { and } \delta_{m}=\frac{N_{o}^{\#}}{S_{1}} \delta_{\Delta w}
$$


the density distribution of $\mathrm{m}$ can be represented as:

$$
f(M)=\frac{\Delta \bar{W}}{\sqrt{2 \pi} M \delta_{\Delta w}} \exp \left[-\frac{(\Delta W-\Delta \bar{W})^{2}}{2 \delta_{\Delta w}^{2}}\right]
$$

Distribution (11) can be used in the assessment of damages from constructive impulse imperfections. Obviously, the smaller the ratio $\frac{\delta_{\Delta w}}{\Delta W}$, the machine better.

Table 1.

\begin{tabular}{|c|c|c|c|c|c|}
\hline \multicolumn{6}{|c|}{ Wednesday-water, t0 15-200 Wednesday with cyclic load 200-800 kPa } \\
\hline \multirow{2}{*}{ Elements } & \multirow{2}{*}{ Material } & \multirow{2}{*}{$\begin{array}{l}\text { Characteristic } \\
\text { lengths double } \\
\text { stroke, } \mathbf{m m}\end{array}$} & \multirow{2}{*}{ Distribution law } & \multicolumn{2}{|c|}{ Parameters of distributions } \\
\hline & & & & $\mathrm{N}(\tau)$ cycle-10-3 & $\mathbf{N}_{\mathrm{E}, \mathbf{r}}$ \\
\hline $\begin{array}{c}\text { 1. Collar } 200 \text { GOST } \\
6678-72\end{array}$ & $\begin{array}{c}\text { Rubber MRTU } 4004 \\
\text { 38-5-1166-64 }\end{array}$ & Abrasions, with 140 & Normal & $0.76(0.14)$ & 3.56 \\
\hline $\begin{array}{l}\text { 2. Cuff } 280 \times 320, \text { GOST } \\
6969-74\end{array}$ & 《-- --- » & 《--------» & $《-»$ & $1.25(0.23)$ & 2.45 \\
\hline $\begin{array}{c}\text { 3. Membrane } 50 \text { GOST } \\
9887-78\end{array}$ & $\begin{array}{c}\text { Rubber MRTU } 3825 \\
\text { 38-5-1166-64 }\end{array}$ & Ustalostnyj wear: 30 & $《-»$ & $6.7(1.45)$ & 1.25 \\
\hline 4. Ratchet & 《--- --- » & Jamming & The exponential & $4.2(4.2)$ & 0.25 \\
\hline $\begin{array}{c}\text { 5. Membrane } 50 \text { GOST } \\
9887-78\end{array}$ & $\begin{array}{c}\text { Rubber MRTU } 3825 \\
\text { 38-5-1166-64 }\end{array}$ & Ustalostnyj wear: 10 & Normal & $1500(500)$ & 0.25 \\
\hline
\end{tabular}

Studies (Table 1) on the definition of the types and distributions of operating time to failure $(\bar{N}, \sigma$ - coverage and root mean square deviation) typical sprinkling systems devices, including the most common elements in hydro automatics: the underground sliding hydrants (elements 1,2), devices, systems automated supervisory control (items 3,4), yaw (element 5) as well as impulse sprinkler machines $(6.7$ items, 8, 9). It is established that the distribution of time to restore those elements, you can characterize the average recovery time $t_{\text {in }}[3,6]$.

\section{Discussion of research results}

As a result of special research received the following relationship between the average service life of parts made of rubber or plastic $\mathrm{t}_{\text {wed }}$, the average number of cycles $\mathrm{N}_{0}^{\#}$ a year and experimental aging value of these materials in the water $\mathrm{t}_{0}$ equal to 6.8 years:

$$
T_{\varphi}=\frac{N_{o} T_{o}}{N_{o}+N_{o}^{\#} T_{o}}
$$

In addition to these activities required to address the optimal level of operational reliability of stationary systems should develop institutional arrangements. For organizational activities of particular importance was the implementation of preventive works and correctly spent time. The timing of prevention is one of the main problems of preventive maintenance, which is closely linked to the content of preventive works and the Organization of their execution [7]. These terms are usually defined in the study the following objective function:

$$
C(t)=\frac{C_{1} M(n)+C_{2} N(t)}{t}
$$

where, with ${ }_{122}$ respectively, the cost of replacement of parts when troubleshooting failures and preventive replacements; (M) $(t), N(t)$-respectively, the average number of replacements in case of failure and preventive services for time $t$.

\section{Scientific conclusions}

Expelled us measure perfection is appropriate with a view to selecting the best design because it is economically summarizing indicators of maintainability of systems security, persistence, and sprinkling.

\section{References}

1. B H Aliyev, IN Aliyev, ZH Aliev (2004) Some Problems of Rural Households in Azerbaijan and Ways of its Solution and Ways of its Solution//IZD-vo Zia Nurlan» Baku pp. 572.

2. Aliev BH, Aliyev ZH W (2005) Irrigated Agriculture in Mountainous and Foothill Regions of Azerbaijan. Baku.

3. Aliev Z H Prospects for the Development of Mountain Agriculture Introduction Euhniki Progressive Irrigation. (Sat. works Research institute erosion and irrigation)/IZD-vo “Tjaraggi” LLC pp. 173-184.

4. Shtepa BG (1975) Advanced Irrigation Methods. M Kolos, 56.

5. Shtepa BG (1983) Advances in Reclamation. M Kolos, 238.

6. Rusetsky OP (2009) Calculation speeds on ridges Weirs-slots and dams flooded polder/a. p. Rusetsky//Reclamation -Minsk N 2(62): 30-41.

7. AP Rusetsky (1999) Modernization of Meliorative Systems and ways to Improve their Efficiency Problems of land reclamation and water resources, at the current stage. 2: 115-119 
(C) $\bigoplus_{\mathbf{B Y}}^{\text {This work is licensed under Creative }}$ To Submit Your Article Click Here: Submit Article

DOI: 10.32474/OAJESS.2018.01.000111

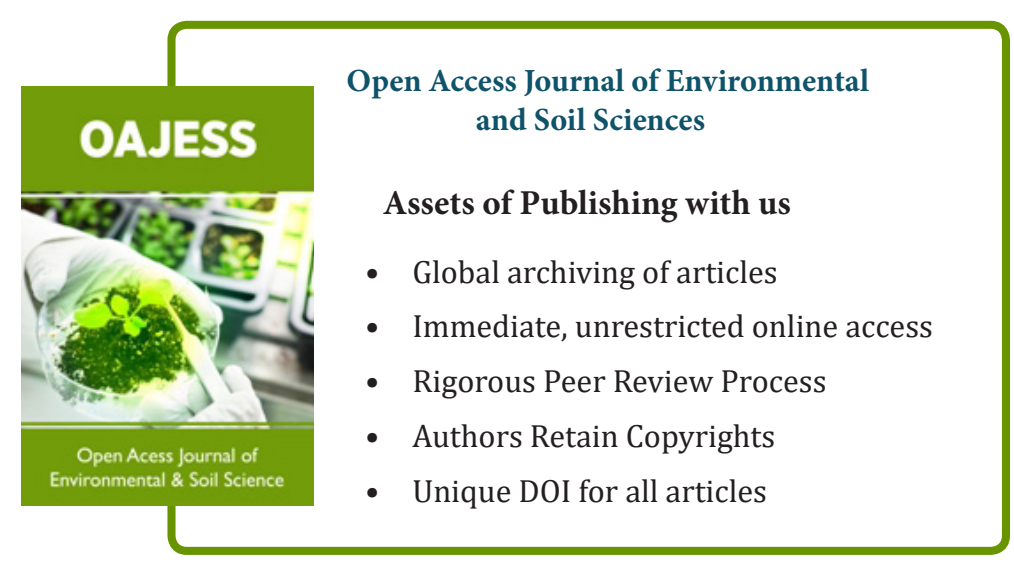

